\title{
Neural Network Model for the Improvement of Strength - Ductility Compromise in Low Carbon Sheet Steels
}

\author{
C. Capdevila, C. Garcia-Mateo, F. G. Caballero and C. García de Andrés \\ MATERALIA Research group \\ www.cenim.csic.es/downloadzone/grupos/giftes0904/GIFTES0904/gitfes uk.html \\ Department of Physical Metallurgy, Centro Nacional de Investigaciones Metalúrgicas (CENIM - \\ CSIC), Avda Gregorio del Amo, 8, 28040, Madrid, Spain.
}

\author{
C. Capdevila : $\underline{\operatorname{ccm} @ \text { cenim.csic.es }}$ \\ C. Garcia-Mateo : $\underline{\operatorname{cgm} @ \text { cenim.csic.es }}$ \\ F.G. Caballero : fgc@cenim.csic.es \\ C. Garcia de Andres : cgda@cenim.csic.es
}

\section{Corresponding Author Carlos Garcia-Mateo}

\begin{abstract}
The goal of the work reported in this paper is to develop a neural network model for describing the evolution of the compromise (UTS $\times$ EL) between ultimate tensile strength (UTS), and elongation (EL) mechanical properties on low carbon sheet steels. The model presented here take into account the influence of 21 parameters describing chemical composition, and thermomechanical processes such as austenite and ferrite rolling, coiling, cold working and subsequent annealing involved on the production route of low carbon steels. The results presented in this paper demonstrate that this model can help on optimizing simultaneously both strength and ductility for the various types of forming operation that the sheets can be subjected to.
\end{abstract}

\section{KEYWORDS}

Neural network; strength; ductility; low carbon steels; processing parameters.

\section{INTRODUCTION}

Vehicle weight reduction, reduced costs, and improved safety performance are the main driving forces behind material selection for automotive applications. High strength steels (HSS) have demonstrated their ability to meet these demands and consequently have been the fastest growing light-weighting material in vehicle structures for the past decade. The evolution in steel technology in recent years has produced new grades of highly formable, advanced high strength steel (AHSS) grades that will continue to meet these automotive demands into the next decade.

Mechanical properties of such steels are main dependent on rolling scheme. The influence of rolling parameters on mechanical properties has been traditionally evaluated with the help of mathematical models, which unfortunately, supply neither a complete nor an exact description of the process. This makes continual recalculation of model parameters necessary, to adapt them to actual process events. A further drawback lies in the fact that the refinement potential for this process has been all but exhausted. To overcome this shortcoming, it was decided to employ an entirely new tool, patterned to human brain: the 'neural network'. Such networks 'learn' from the massive volume of incoming data and the relationships involved and gain experience from systematic observation of recurring events. This makes them capable of supporting traditional mathematical models or replacing them entirely. Their learning ability also enables neural networks to adapt continuously to changing process states. 
This paper provides an example of how neural network modelling could be incorporated into the optimization process of steels for automotive applications and how the rolling processing parameters affects the strength and ductility compromise of such steels that satisfy the increasing crash performance requirements placed on vehicle designs.

\section{BUILD OF THE MODEL}

\section{The experimental database}

The strength - ductility compromise such as the product between ultimate tensile strength (UTS) and elongation (El), i.e. UTS $\times \mathrm{El}$ (called strength - ductility compromise hereafter), in any model ideally require a complete description of the chemical composition and processing parameters. A literature survey ${ }^{1-5}$ allows us to collect 590 individual cases where detailed chemical composition, hot-rolling and ferritic rolling processing parameters, coiling temperature, cold reduction and isothermal temperature values were reported. Table 1 shows the list of 20 input variables used for the UTS $\times$ EL properties analysis.

The variables considered here tend to cover most of the stage of hot rolling for sheet steels. Finishing rolling temperature (FRT), reduction in austenite (Red-A) and/or ferrite field (Red-F), cooling rate (CRate) down to coiling temperature (CT) are the parameters selected to describe the hot rolling process. Chemical composition, in particular carbon (C), manganese (Mn), silicon ( $\mathrm{Si}$ ), phosphor $(\mathrm{P})$, sulphur $(\mathrm{S})$, aluminium $(\mathrm{Al})$ and nitrogen $(\mathrm{N})$ contents have been considered. Microalloying additions have been also considered in this study, in particular titanium (Ti), niobium $(\mathrm{Nb})$ and vanadium $(\mathrm{V})$ additions. Cold rolling process through the cold reduction (CR) has been considered. Finally, annealing stage has been included in the models developed through the following parameters: heating rate (HR) from room temperature up to annealing temperature (T), isothermal holding time $(\mathrm{t})$, and cooling rate down to room temperature (Cooling) have been considered as the most characteristic parameters of this stage.

\section{Brief description of neural network}

The aim is to be able to estimate the UTS $\times \mathrm{EL}$ as a function of the variables listed in Table 1 . In the present case, the network was trained using a randomly chosen of 296 examples from a total of 590 available; the remaining 294 examples were used as new experiments to test the trained network. Linear functions of the inputs $x_{j}$ are operated by a hyperbolic tangent transfer function

$$
h_{i}=\tanh \left(\sum_{j} w_{i j}^{(1)} x_{j}+\theta_{i}^{(1)}\right)
$$

So that each input contributes to every hidden unit. The bias is designated $\theta_{i}^{(l)}$ and is analogous to the constant that appears in linear regression. The strength of the transfer function is in each case determined by the weight $w_{i j}{ }^{(I)}$. The transfer to the output $y$ is linear

$$
y=\sum_{i} w_{i}^{(2)} h_{i}+\theta^{(2)}
$$

This specification of the network structure, together with the set of weights, is a complete description of the formula relating the inputs to the output. The weights were determined by training the network and the details are described by MacKay ${ }^{6-7}$. The training involves a minimization of the regularized sum of squared errors. The term $\sigma_{v}$ used below was the framework estimation of the noise level of the data. The complexity of the model was controlled by the number of hidden units. 
It is observed that the inferred noise level decreases monotonically as the number of hidden units increase. However, the complexity of the model also increases with the number of hidden units. A high degree of complexity may not be justified, and in an extreme case, the model may in a meaningless way attempt to fit the noise in the experimental data. MacKay ${ }^{8-9}$ has made a detailed study of this problem and defined a quantity (the 'evidence') which comments on the probability of a model. In circumstances where two models give similar results for the known data, the more probable model would be predicted to be that which is simpler; this simple model would have a higher value of evidence. The evidence framework was used to control $\sigma_{v}$. The number of hidden units was set by examining performance on test data. A combination of Bayesian and pragmatic statistical techniques were therefore used to control the complexity of the model ${ }^{10}$. Also, it was found shows that a large number of hidden units did not give significantly lower values of $\sigma_{v}$; indeed, eleven hidden units were found to give a reasonable level of complexity to represent the variations of UTS $\times$ EL as a function of the input variables of Table 1 .

However, it is possible that a committee of models can make a more reliable prediction than an individual model. The committee of models could then be formed by combining the prediction of the best $L$ models, where $L=1,2, \ldots$ The size of the committee is therefore given by the value of $L$. The test error of the predictions made by a committee of $L$ models, ranked $1,2 \ldots q \ldots L$, each with $n$ lines of test data, is calculated in a similar manner to the test error of a single model:

$$
\begin{aligned}
& T_{\text {en }}=0.5 \sum_{n}\left(\overline{y_{n}}-t_{n}\right)^{2} \\
& \bar{y}_{n}=\frac{1}{L} \sum_{q} y_{n}^{(q)}
\end{aligned}
$$

where $y_{n}^{(q)}$ is the set of predictions made by the model and $t_{n}$ is the set of target (experimental) values. For the particular case treated in this work, the combined test error goes through a minimum for the committee made up of two models.

Fig.1 illustrate the significance $\left(\sigma_{w}\right)$ of each of the input variables, as perceived by the neural network, in influencing the strength - ductility compromise. The metallurgical significance of the results predicted by the model is discussed below, but a first approximation of the influence of each one of the variables studied could be drawn from a close observation of Fig. 1.

As general comment, it is clear that the annealing temperature $(\mathrm{T})$ after cold rolling (CR), together with holding time at such temperature $(\mathrm{t})$, clearly have a large intrinsic effect, which is consistent with experimental evidences reported in the literature. ${ }^{11-12}$ Likewise, the heating rate up to annealing temperature (HR) and cooling rate after annealing (Cooling) specially, have an important effect on strength - ductility compromise.

In terms of hot rolling processing parameters, finishing rolling temperature (FRT), reduction in austenite (Red-A) or ferrite region (Red-F) have a relative low influence in the model. The influence of cooling rate (CRate) after hot rolling down to coiling temperature is almost negligible. It is surprising the small effect that coiling temperature (CT) has on the model developed. This is because of the small range of temperatures studied (see Table 1). Although the hypothetical range of CT values is from 20 to $750{ }^{\circ} \mathrm{C}$, the average value is $654{ }^{\circ} \mathrm{C}$, which indicate that most of the data fall in the range of $600-700{ }^{\circ} \mathrm{C}$. This can explain why the models are not very sensitive to CT. More data covering additional $\mathrm{CT}$ are required.

Regarding the influence of chemical composition, it is clear that carbon content (C) affect significantly the compromise. Manganese (Mn), silicon ( $\mathrm{Si}$ ), aluminium ( $\mathrm{Al}$ ), and phosphor (P) contents have a negligible influence on strength - ductility compromise model. Finally, it is worth 
mentioning the fairly important influence that microalloying element such as $\mathrm{Ti}$ and $\mathrm{Nb}$ ( $\mathrm{Ti}$ and $\mathrm{Nb}$, respectively) have on strength - ductility compromise.

\section{RESULTS AND DISCUSSION}

\section{Influence of chemical composition.}

Fig. 2 shows the evolution of UTS $\times$ EL with carbon content. Steel tested for calculations is listed in the first column of Table 2, with carbon content ranging from 0.001 to $0.1 \mathrm{wt} . \%$. It is clear from this figure that there is a carbon content which induces the maximum value of UTS $\times$ EL.

On the other hand, Fig. 3 shows the evolution of UTS $\times$ EL compromise varying simultaneously titanium and carbon content. Steel tested for calculations is listed in the second column of Table 2. It is clear that the best combination of properties are achieved for relative low combination of $\mathrm{Ti}$ and $\mathrm{C}$, where $\mathrm{Ti}$ is added in low enough proportion so no excess precipitates exits, since precipitates ensure higher strength but poorer ductility. This result is consistent with reported data on literature $^{13-14}$ which confirm the better combination of properties, in general, of HSLA (high strength low alloy) as compare with ELC (extra low carbon) steels.

Moreover, differences in the influence of $\mathrm{C}$ and $\mathrm{Ti}$ on UTS $\times \mathrm{EL}$ are detected between the two annealing temperatures $\left(850\right.$ and $\left.700{ }^{\circ} \mathrm{C}\right)$ tested. As it will be described in following sections, the strong influence of annealing temperature on the strength - ductility compromise is due to the recrystallisation state of the microstructure after annealing. It is observed that Ti content has a weak influence on UTS $\times$ EL after annealing at $850^{\circ} \mathrm{C}$. This is because full recrystallised microstructure is obtained even after a short holding time such as $10 \mathrm{~s}$ at this temperature. However, at $700{ }^{\circ} \mathrm{C}$ recrystallisation proceeds more sluggish than at $850{ }^{\circ} \mathrm{C}$, and the increasing amount of Ti promote precipitation events that can retard recrystallisation even more. Thus, UTS $\times$ EL compromise is affected, which is consistent with the results presented in Fig.3.

\section{Influence of cooling rate}

Cooling rate after annealing has a reasonable influence on UTS $\times$ EL model according to Fig.4. Steel tested for calculations is listed in the third column of Table 2. Likewise, it has been observed ${ }^{15}$ that $^{\circ}$ recrystallisation has not finished completely during the short annealing of $10 \mathrm{~s}$ at $700{ }^{\circ} \mathrm{C}$ in the steel listed in Table 2 for Fig. 4. Therefore, the faster the cooling rate after annealing is, the finer the microstructure is, which should lead to the strengthening of the material. On the other hand, dissolution of cementite is produced during heating and holding at $700{ }^{\circ} \mathrm{C}$ in the annealing processes. If cooling rate is slow enough, carbon will precipitate during subsequent cooling contributing to the strengthening of the material. Moreover, this precipitation could be avoided for fast cooling after annealing, producing a strengthening for solid solution of carbon of the microstructure.

The strengthening of the microstructure leads to a subsequent poorness of ductility, which should lead to a reduction of UTS $\times$ EL product. In this sense, Fig. 4 shows that as cooling rate increases, UTS $\times$ EL decreases down to a minimum value reached at $350{ }^{\circ} \mathrm{Cs}^{-1}$, which is consistent with the above idea that increase cooling leads to a strengthening of the material. However, higher cooling rates produce a substantial increase of UTS $\times \mathrm{EL}$, which could mean that the increase of strength is not follow by the corresponding and proportional decrease of ductility. However, the huge error bars for fast cooling rates, which indicate a lack of data in the dataset for these cooling rates, does not allow extracting reliable data from the models, although the trend of data is correct. Further increase of data in this range is required.

\section{Influence of Annealing Temperature}


In order to analyse the effect of annealing temperature after cold rolling, the steel listed in the fourth column of Table 2 has been selected, i.e. an extra low carbon steel with $\mathrm{CR}=75 \%$. Fig. 5 shows the experimentally obtained evolution of UTS and EL mechanical properties with annealing temperature. It is clear that this temperature affects enormously the evolution of such mechanical properties. This is a consequence of static recrystallisation process, which leads to an increase of ductility in detriment of strength.

There is an interest on optimize the better strength and ductility values both at the same time in this extra low carbon sheet steels. The aim is to develop steel sheet products having a range of high strength levels in combination with adequate ductility for the various types of forming operation that the sheets can be subjected to. During cold rolling, which is a necessary stage in production, the steel becomes intensely hardened but loses almost all its ductility. During conventional processing this strengthening is sacrificed to restore ductility by a conventional annealing. Then, if higher strength is demanded, it is achieved by either alloying or by special heat treatments at higher temperatures. The UTS $\times$ EL model presented here was built with the intention of indicate the parameters at which it could be possible to retain as much of the strength from cold rolling as possible while at the same time restoring adequate ductility by controlled low temperature annealing. In this sense, Fig. 6 shows the combined influence of cold reduction (CR) and annealing temperature. It is clear that the best results are obtained for cold reduction in the order of $70 \%$ and intermediate annealing temperatures of $750{ }^{\circ} \mathrm{C}$.

It was also analysed the effect of annealing time for a fixed annealing temperature of $700{ }^{\circ} \mathrm{C}$. Steel base for calculations is listed in the fifth column of Table 2. Results are presented in Fig.7. It is pretty clear that the best combination of properties is obtained for intermediate annealing times, i.e. 30 seconds, which for low CR values ensure a non complete recrystallise microstructure. Therefore, the results presented in Fig. 6 and 7 are consistent with the broad idea that a partially recrystallise microstructure will strength the material but maintaining considerable levels of ductility at the same time.

Finally, the role of cooling rate after annealing has been studied. Fig.8 shows the combined effect of carbon and annealing temperature on UTS $\times$ EL parameter for two different cooling rates after annealing with a base steel listed in the sixth column of Table 2 . It is clear that no significant effect of cooling rate is observed. Likewise, it is clear that the better combination of strength and ductility is produced at relatively low carbon contents and annealing temperatures around $700{ }^{\circ} \mathrm{C}$. The graphs also show that the best combination of properties is achieved at annealing temperatures around 700 ${ }^{\circ} \mathrm{C}$. These results are fully consistent with the ones shown in Fig. 5 and 6 since this intermediate annealing temperatures ensure a partially recrystallise microstructure. Therefore, one of the initial assumptions of the project regarding the best conditions for the optimizations of properties could be achieved with the present model.

\section{CONCLUSIONS}

The neural network model under a Bayesian framework to study the variation of UTS $\times$ EL with 21 parameters including chemical composition, and processes such as austenite rolling, ferritic rolling, coiling, cold working and subsequent annealing on low carbon steels have been successively develop. It was obtained that the annealing temperature after cold rolling, together with holding time at such temperature, clearly has a large intrinsic effect. Processing parameters of hot rolling such as finishing rolling temperature (FRT), reduction in austenite (Red-A) or ferrite region (Red-F) have, by contrast, a relative low influence on the UTS $\times$ EL model. Moreover, the influence of cooling rate after hot rolling down to coiling temperature is almost negligible. 
Regarding the chemical composition, it was obtained that carbon content, and especially microalloying elements such as $\mathrm{Ti}$ and $\mathrm{Nb}$, significantly affects the UTS $\times \mathrm{EL}$ parameter. The developed model predicts the strong influence of low amounts of Ti on significantly increasing the strength - ductility compromise in steels with ultra- and extra-low carbon content.

\section{Acknowledgements}

The authors acknowledge financial support from European Community and Spanish Ministerio de Educación y Ciencia in the form of ECSC Project (ECSC 7210-PR-368) and a Complementary Project (MAT 2002-10810E). Authrs acknowledge T. Iung (France) from Arcelor Reserch, J. Spearl from Voest Alpine Stahl (Austria), M. Bartieri from Centro Sviluppo di Materiali (Italy), and Bevis Hutchinson from KIMAB (Sweden) for the fruitful discussions. C. García-Mateo would like to thank the Spanish Ministerio de Ciencia y Tecnología for the financial support in the form of a Ramon y Cajal contract. The authors also are grateful to Neuromat Ltd. for the provision of the neural network software used in this work.

\section{References}

1. C. Bertrand, J. Albarrán, C. Richard, U. Lotter, S. Medina, M. De Sanctus, Final Report EUR 20936 EN, Contract No 7210-PR/158, ISBN 92-894-7493-9, 2004.

2. A. Pichler, C. Commendo, G. Hibernig, A. De Paepe, G. Bourdon, J.C. Herman, A. Bodin, U. Lotter, L. Zhang, D. Artymowicz, B. Hutchinson, Final Report EUR 21136 EN, Contract No 7210-PR/163, ISBN 92-894-8068-8, 2004

3. V.K. Cuddy, H. Merkle, A. Richardson, O. Hudin, A. Hildebrand, H. Richter, T. Nilsson, J. Larsson, Final Report EUR 21909 EN, Contract No 7210-PR/179, ISBN 92-79-00139-6, 2005.

4. S. R. Daniel, B. Hutchinson, L. Ryde, G. Beyer, H. J. Grabke, C. Van Durme, W. Bleck, J. Ohlert, G. N. Haidemenopoulos, A. N. Vasilakos, A. Pichler, P. Stiaszny, Final Report EUR 20099 EN, Contract No 7210-EC/115-211-810-116-702-117-901, ISBN 92-894-9106-7, 2002.

5. A. Pichler, H. Spindler, C. Van Durme, P. E. Di Nunzio, K. Spiradek, S. Geisler, W. Bleck, Final Report EUR 19878 EN, Contract No 7210-EC/119-120-121-219-408, ISBN 92-894-1472-3, 2001.

6. D.J.C. MaKay: Neural Comput., 1992, 4, 698-705.

7. D.J.C. MaKay: Darwin college J., 1993, March, 81-93.

8. D.J.C. MaKay: Neural Comput., 1992, 4, 415-422.

9. D.J.C. MaKay: Neural Comput., 1992, 4, 448-460.

10. H.K.D.H. Bhadeshia: ISIJ Int., 1999, 39, 965-979.

11. W.B. Hutchinson, International Metals Reviews, 1984, 29, 25-42.

12. B. Hutchinson, Phil. Trans. R. Soc. Lond. A, 1999, 357, 1471-1485.

13. A. Haldar, R.K. Ray, Mater. Sci. Engineer. A, A391, 2005, 402-407.

14. C. Capdevila, T. De Cock, C. García-Mateo, F. G. Caballero, and C. García de Andrés, Materials Science Forum, 2005, 500-501, 803-813.

15. C. Capdevila, T. De Cock, F.G. Caballero, C. García-Mateo, C. García de Andrés, Materials Science Forum, 2004, 467-470, 863-868. 


\section{Figure Captions}

Figure 1. Histogram showing the significance of input variables in influencing the strength ductility compromise model.

Figure 2. Influence of carbon content on the strength - ductility compromise.

Figure 3. Combined effect of Ti and C on UTS $\times$ EL parameter for annealing temperatures of $850{ }^{\circ} \mathrm{C}$ and $700{ }^{\circ} \mathrm{C}$. (UTS $\left.\times \mathrm{EL}\right) \pm$ error provides with the uncertainty in model's predictions.

Figure 4. Evolution of UTS $\times$ EL with cooling rate after annealing.

Figure 5. Evolution of UTS and EL with annealing temperature (isothermal holding time of 10s).

Figure 6. Combined effect of CR and annealing temperature. (UTS $\times$ EL) \pm error provides with the uncertainty in model's predictions.

Figure 7. Combined effect of CR and annealing time for a temperature of $700{ }^{\circ} \mathrm{C}$. (UTS $\left.\times \mathrm{EL}\right) \pm$ error provides with the uncertainty in model's predictions.

Figure 8. Combined effect of carbon and annealing temperature on UTS $\times$ EL for cooling rate after annealing of $1{ }^{\circ} \mathrm{C} \mathrm{s}^{-1}$ and $100{ }^{\circ} \mathrm{C} \mathrm{s}^{-1}$. (UTS $\times$ EL) \pm error provides with the uncertainty in model's predictions. 


\section{Tables}

Table 1. Variables that influence strength - ductility compromise. SD is standard deviation.

\begin{tabular}{ccccc}
\hline & Minimum & Maximum & Average & SD \\
\hline $\mathrm{FRT} /{ }^{\circ} \mathrm{C}$ & 400 & 930 & 916.9435 & 47.7139 \\
$\mathrm{Red}-\mathrm{A} / \%$ & 0 & 87 & 83.1558 & 11.0752 \\
$\mathrm{Red}-\mathrm{F} / \%$ & 0 & 92 & 1.5753 & 11.9455 \\
$\mathrm{Crate} /{ }^{\circ} \mathrm{Cs}{ }^{-1}$ & 10 & 400 & 31.3545 & 71.3761 \\
$\mathrm{CT} /{ }^{\circ} \mathrm{C}$ & 20 & 750 & 654.1113 & 100.2767 \\
$\mathrm{C} / \mathrm{wt} \%$ & 0.002 & 0.08 & 0.0269 & 0.0247 \\
$\mathrm{Mn} / \mathrm{wt} . \%$ & 0.034 & 1.254 & 0.3136 & 0.1533 \\
$\mathrm{Si} / \mathrm{wt} \%$ & 0.001 & 0.283 & 0.007 & 0.0202 \\
$\mathrm{P} / \mathrm{wt} \%$ & 0.001 & 0.073 & 0.033 & 0.0295 \\
$\mathrm{~S} / \mathrm{wt} . \%$ & 0.001 & 0.022 & 0.0098 & 0.0053 \\
$\mathrm{Al} / \mathrm{wt} . \%$ & 0.001 & 0.159 & 0.0413 & 0.0108 \\
$\mathrm{~N} / \mathrm{wt} . \%$ & 0.001 & 0.005 & 0.0037 & 0.001 \\
$\mathrm{Ti} / \mathrm{wt} . \%$ & 0 & 0.083 & 0.0135 & 0.0138 \\
$\mathrm{~V} / \mathrm{wt} \%$ & 0 & 0.003 & 0.0001 & 0.0005 \\
$\mathrm{Nb} / \mathrm{wt} . \%$ & 0 & 0.022 & 0.0094 & 0.0067 \\
$\mathrm{CR} / \%$ & 0 & 90 & 70.851 & 10.024 \\
$\mathrm{HR} /{ }^{\circ} \mathrm{Cs}{ }^{-1}$ & 4 & 3000 & 490.2877 & 873.822 \\
$\mathrm{~T} /{ }^{\circ} \mathrm{C}$ & 546 & 1112 & 772.298 & 94.3922 \\
t/s & 0 & 89 & 16.9065 & 24.0136 \\
$\mathrm{Cooling} /{ }^{\circ} \mathrm{Cs}{ }^{-1}$ & 10 & 500 & 311.3185 & 226.3589 \\
\hline $\mathrm{UTSxEl} / \mathrm{MPa} \%$ & 299 & 16802 & 10732.494 & 1206.8084 \\
\hline
\end{tabular}


Table 2. Parameters used for calculations

\begin{tabular}{cccccccc}
\hline & Fig. 2 & Fig. 3 & Fig. 4 & Fig. 5 & Fig.6 & Fig. 7 & Fig. 8 \\
\hline $\mathrm{FRT} /{ }^{\circ} \mathrm{C}$ & 900 & 900 & 900 & 900 & 900 & 900 & 900 \\
$\mathrm{Red}-\mathrm{A} / \%$ & 85 & 85 & 85 & 85 & 85 & 85 & 85 \\
$\mathrm{Red}-\mathrm{F} / \%$ & 0 & 0 & 0 & 0 & 0 & 0 & 0 \\
$\mathrm{Crate} /{ }^{\circ} \mathrm{Cs}{ }^{-1}$ & 10 & 10 & 10 & 10 & 10 & 10 & 10 \\
$\mathrm{CT} /{ }^{\circ} \mathrm{C}$ & 700 & 750 & 700 & 750 & 750 & 750 & 750 \\
$\mathrm{C} / \mathrm{wt} \%$ & Variable & Variable & 0.014 & 0.01 & 0.01 & 0.01 & Variable \\
$\mathrm{Mn} / \mathrm{wt} . \%$ & 0.8 & 0.2 & 0.2 & 0.2 & 0.2 & 0.2 & 0.2 \\
$\mathrm{Si} / \mathrm{wt} \%$ & 0.04 & 0.02 & 0.02 & 0.02 & 0.02 & 0.02 & 0.02 \\
$\mathrm{P} / \mathrm{wt} . \%$ & 0.001 & 0.001 & 0.001 & 0.001 & 0.001 & 0.001 & 0.001 \\
$\mathrm{~S} / \mathrm{wt} \%$ & 0.003 & 0.001 & 0.001 & 0.001 & 0.001 & 0.001 & 0.001 \\
$\mathrm{Al} / \mathrm{wt} . \%$ & 0.04 & 0.04 & 0.04 & 0.04 & 0.04 & 0.04 & 0.04 \\
$\mathrm{~N} / \mathrm{wt} \%$ & 0.0023 & 0.003 & 0.003 & 0.003 & 0.003 & 0.003 & 0.003 \\
$\mathrm{Ti} / \mathrm{wt} . \%$ & 0 & Variable & 0 & 0 & 0 & 0 & 0 \\
$\mathrm{~V} / \mathrm{wt} \%$ & 0 & 0 & 0 & 0 & 0 & 0 & 0 \\
$\mathrm{Nb} / \mathrm{wt} . \%$ & 0 & 0 & 0 & 0 & 0 & 0 & 0 \\
$\mathrm{CR} / \%$ & 70 & 70 & 75 & 75 & Variable & Variable & 75 \\
$\mathrm{HR} /{ }^{\circ} \mathrm{Cs}{ }^{-1}$ & 10 & 5 & 10 & 5 & 5 & 5 & 5 \\
$\mathrm{~T} /{ }^{\circ} \mathrm{C}$ & 600 & 850,700 & 700 & Variable & Variable & 700 & Variable \\
t/s & 10 & 10 & 10 & 10 & 10 & Variable & 10 \\
$\mathrm{Cooling} /{ }^{\circ} \mathrm{Cs}{ }^{-1}$ & 10 & 10 & Variable & 10 & 10 & 10 & 1,100 \\
\hline
\end{tabular}


Fig_1

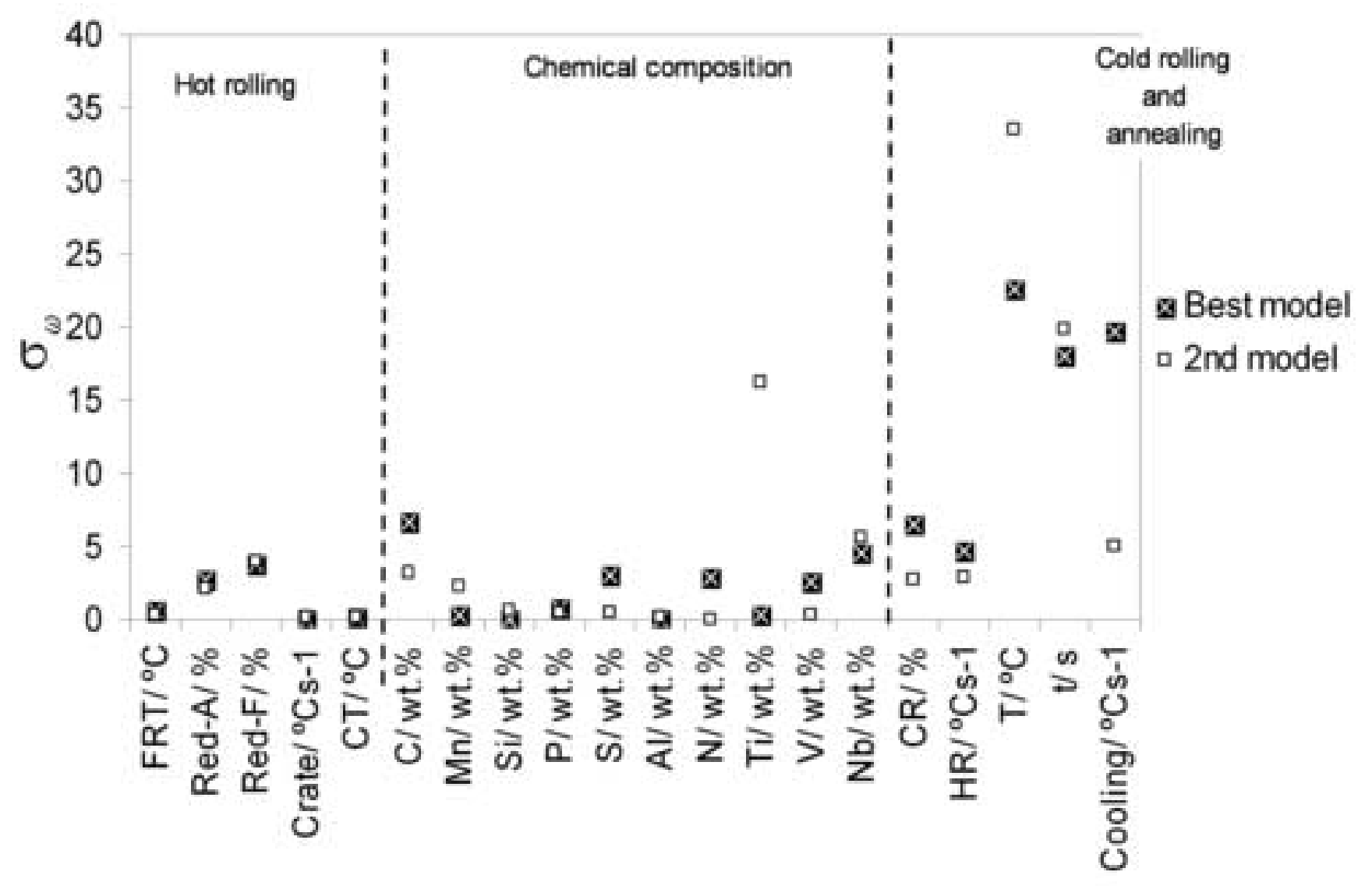


Fig_2

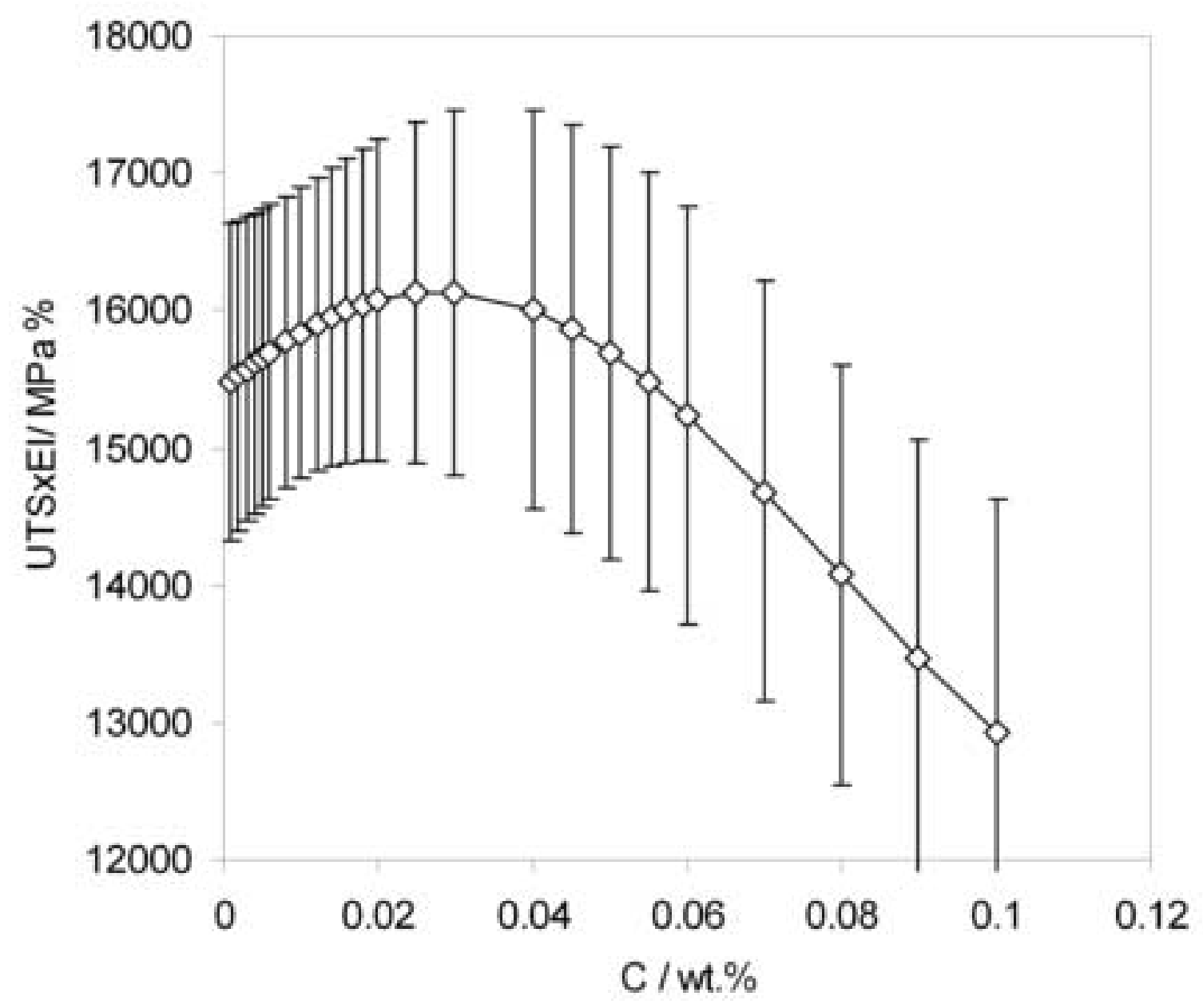


Fig_3_a

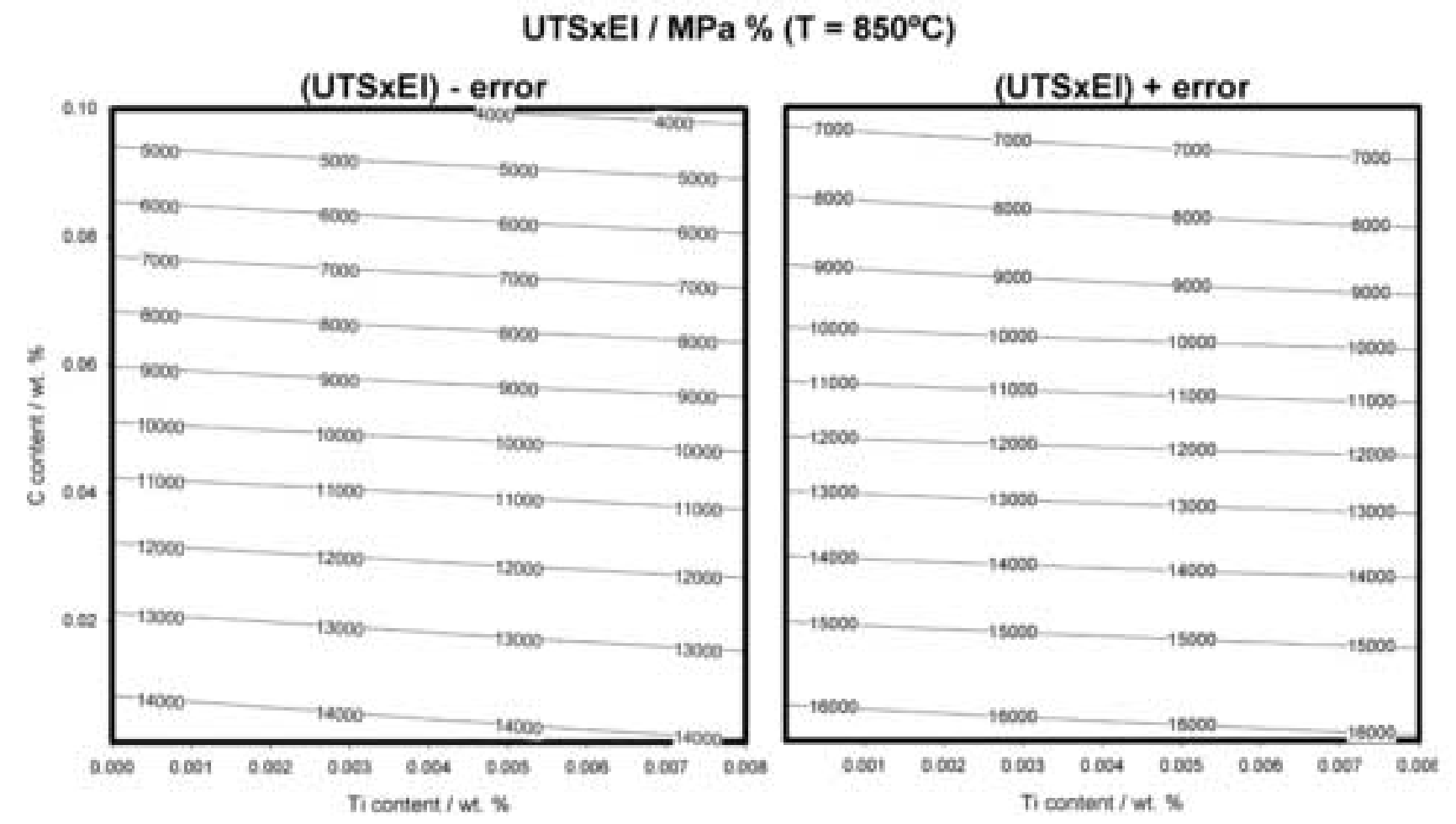


Fig_3_b

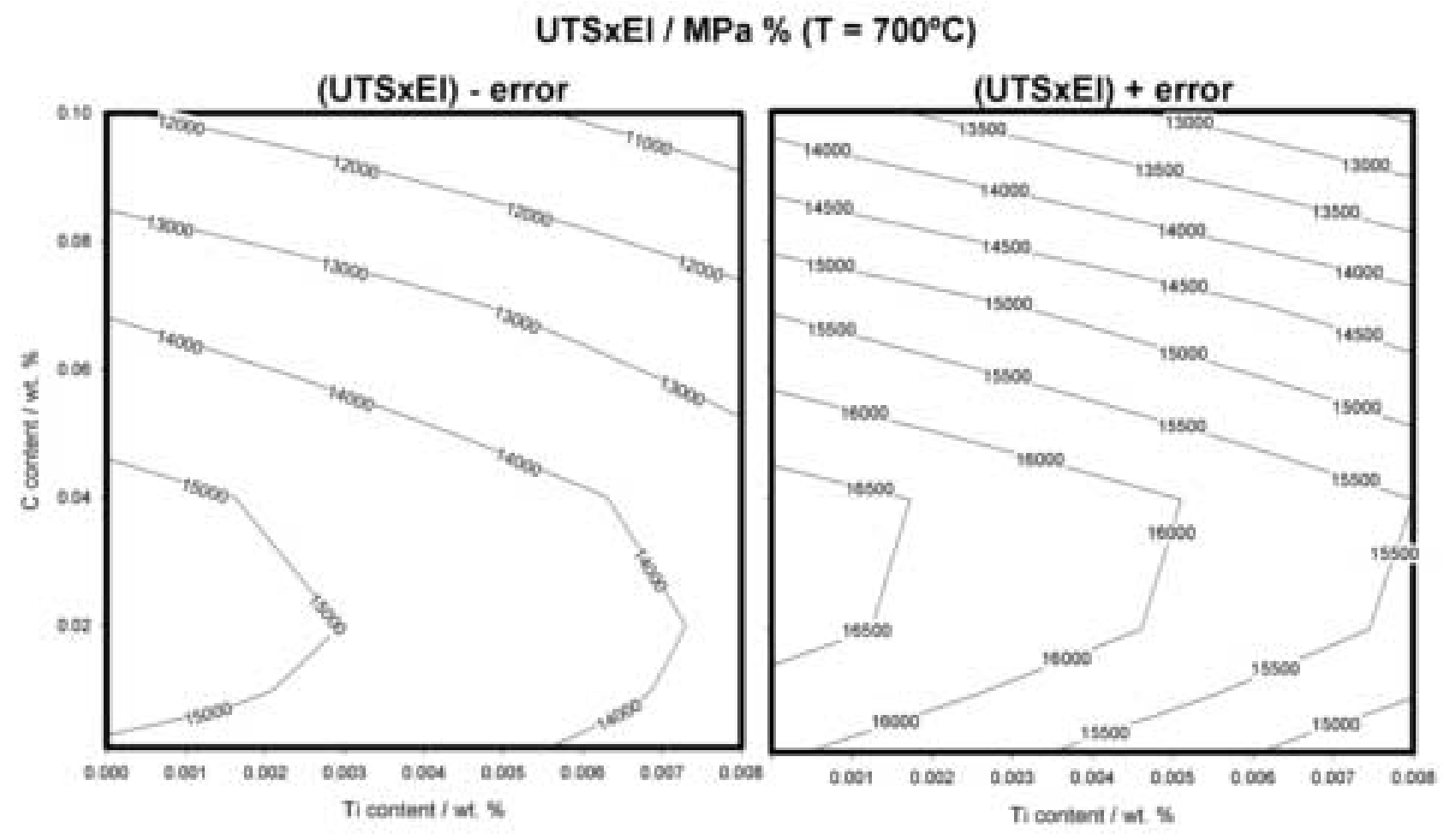

UTSXEI $/ \mathrm{MPa} \%\left(\mathrm{~T}=700^{\circ} \mathrm{C}\right)$ 


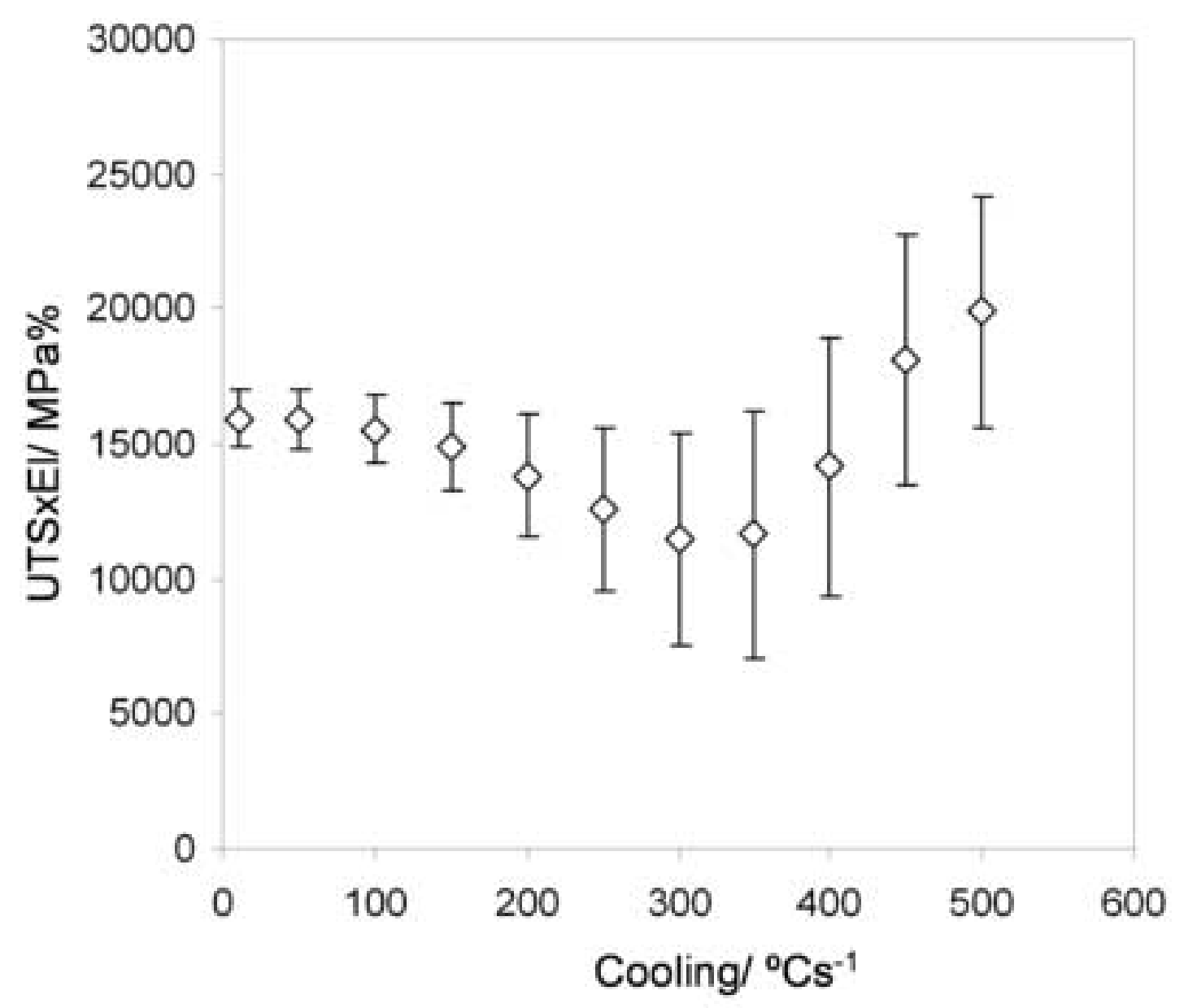

Fig_4 
Fig_5

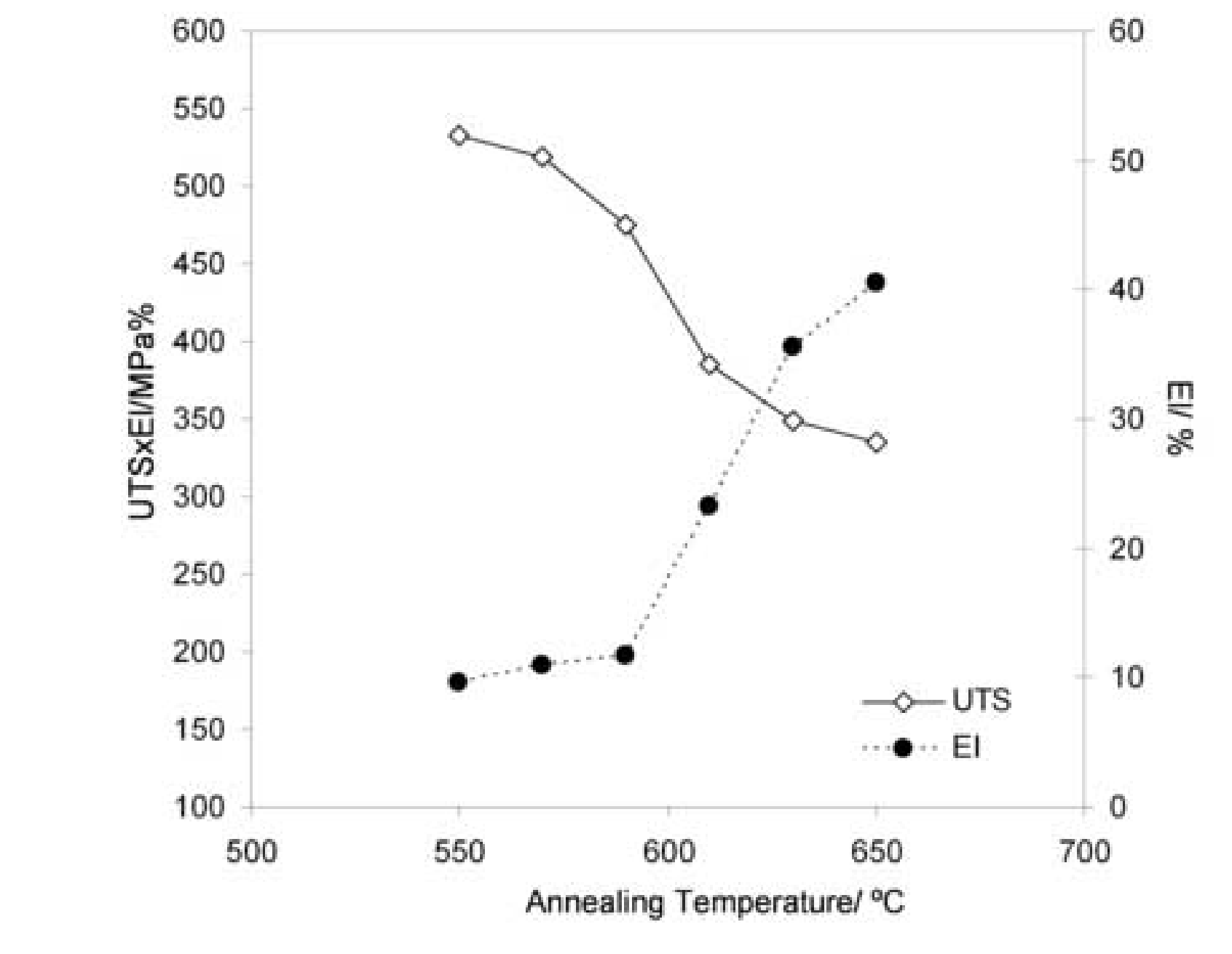

Fig_5

.

.

.

. 
Fig_7

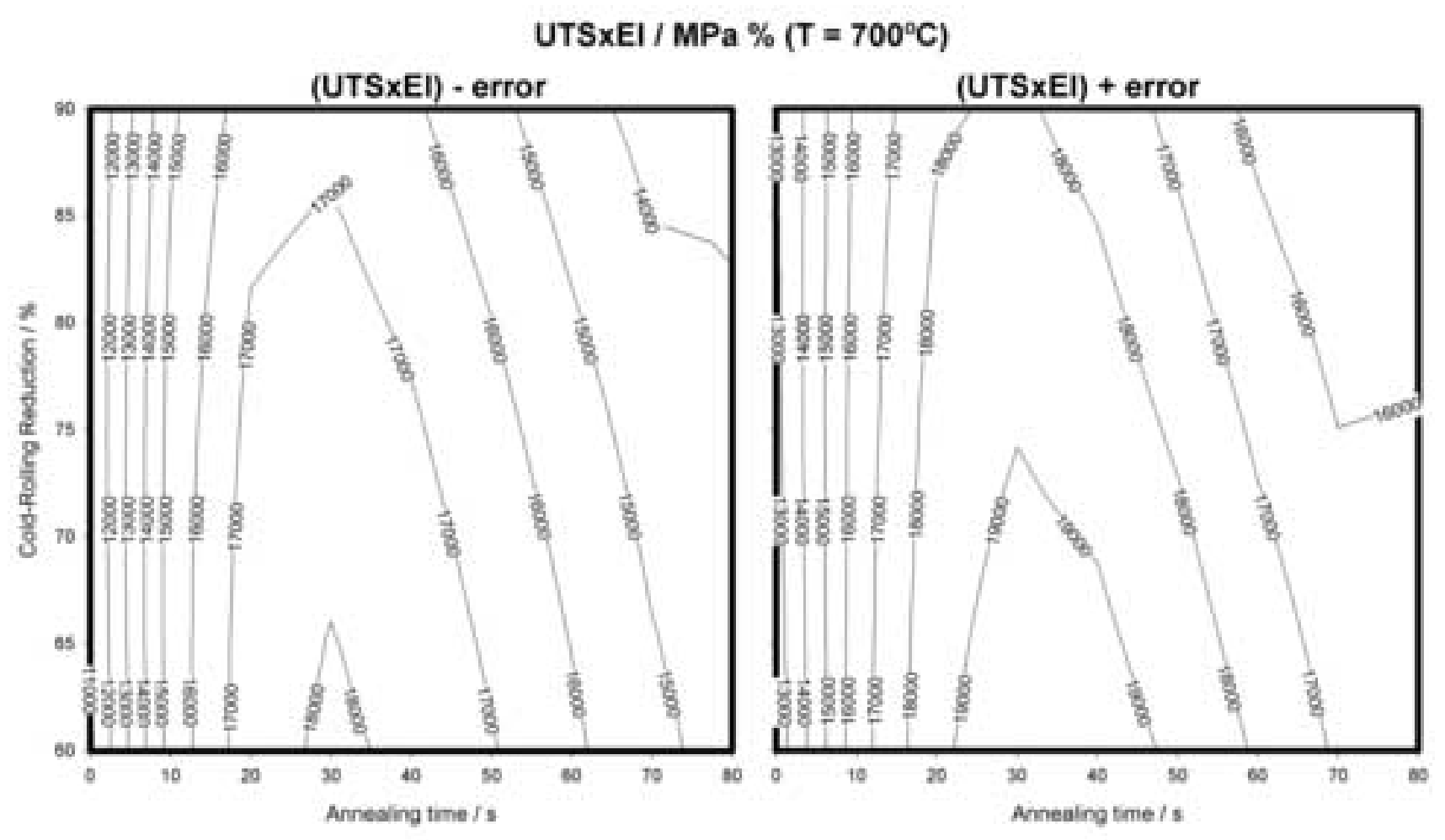




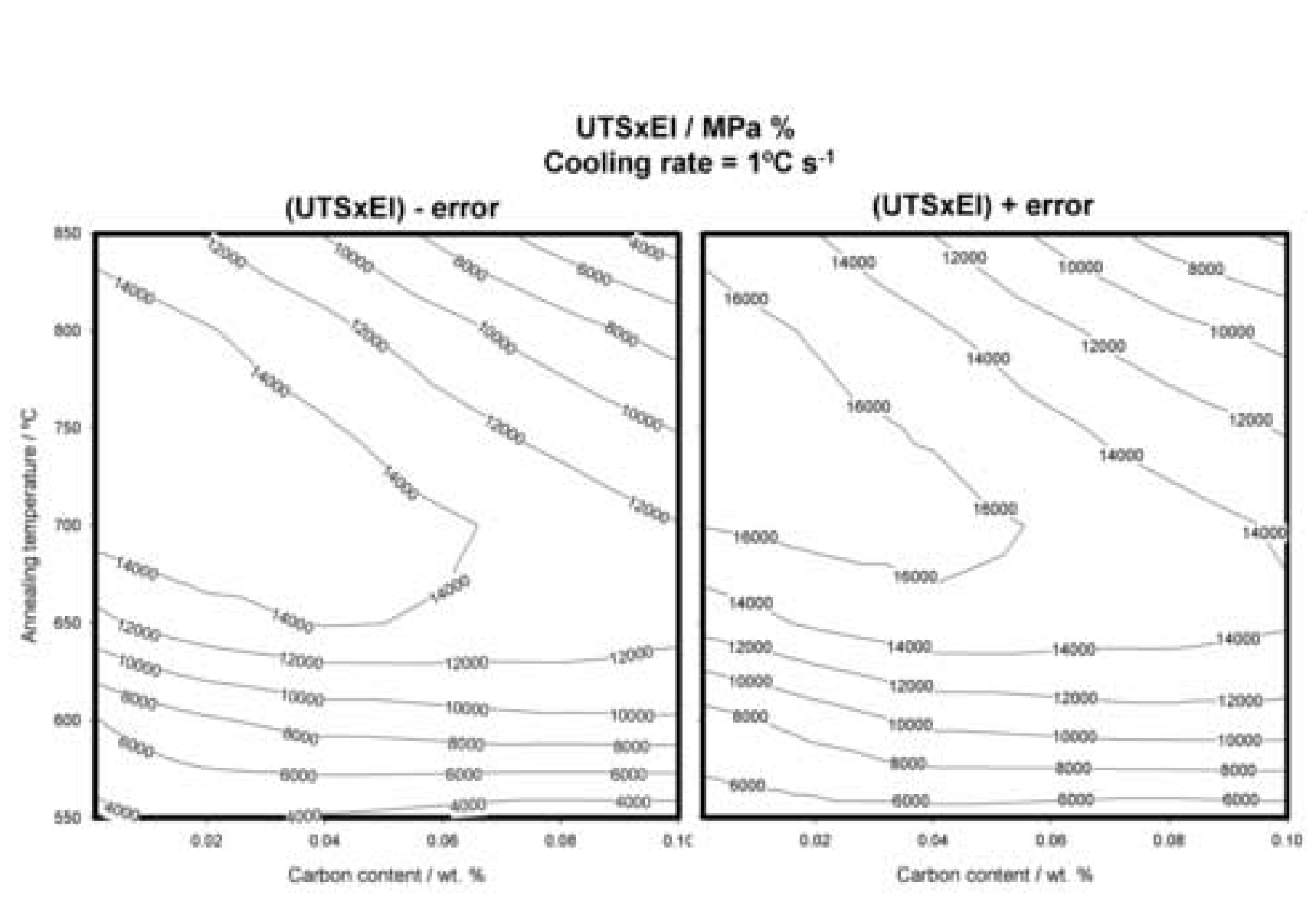

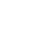

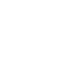

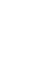
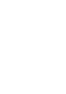
Fig_8_b

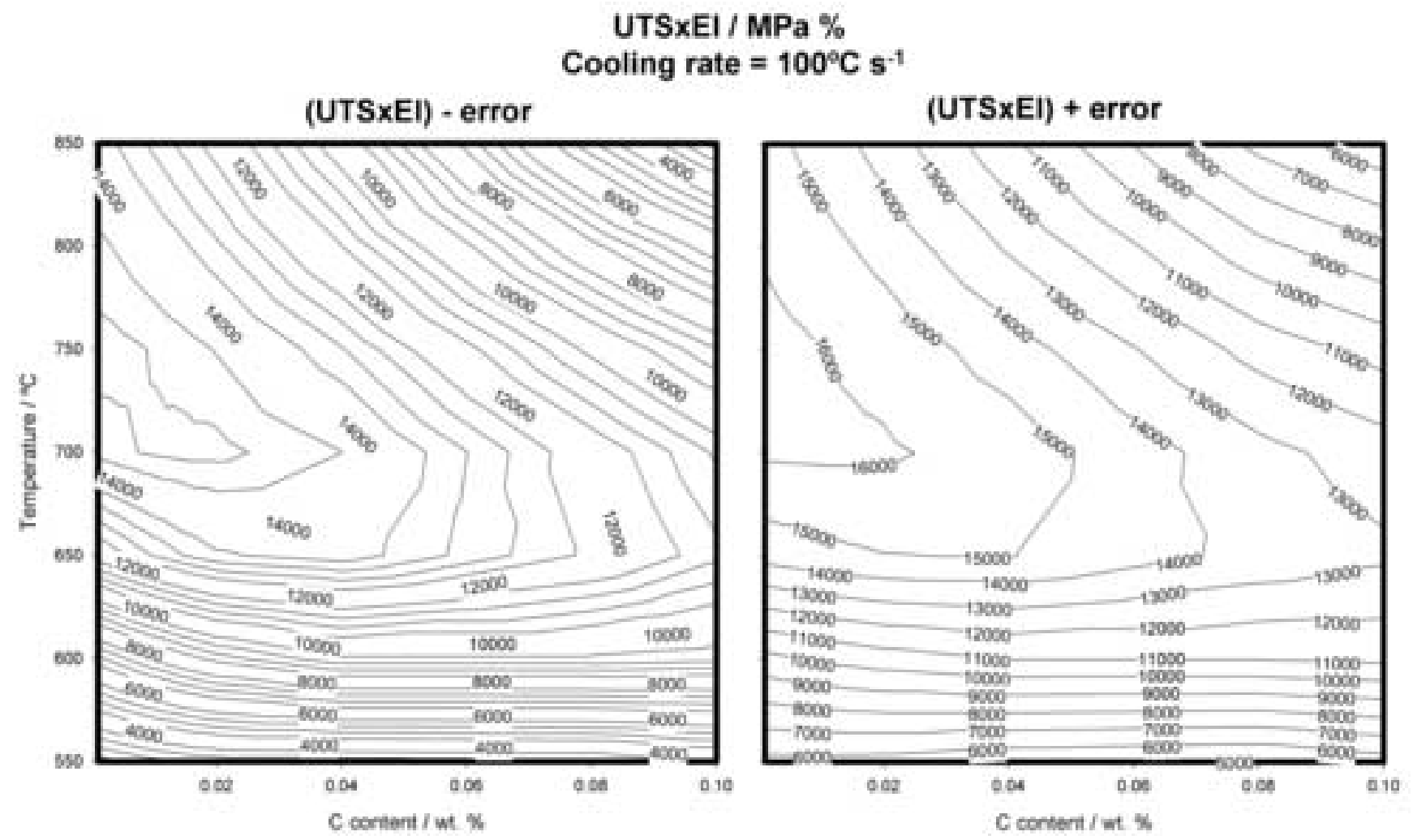

